\title{
ĐỐI CHIẾU CHẨN ĐOÁN TẾ BÀO HỌC DƯỚI HƯỚNG DẪN CỦA SIÊU ÂM VỚI CHẨN ĐOÁN MÔ BỆNH HỌC SAU PHẪU THUÂTT BƯớU NHÂN TUYẾN GIÁP TẠI THÁI BÌNH NĂM 2019
}

\section{TÓM TẮT.}

Mục tiêu: Đối chiếu chẩn đoán tế bào hoc dưới hướng dẫn của siêu âm với chẩn đoán mô bệnh học sau phẫu thuật các bướu nhân tuyến giáp tại Thái Bình năm 2019. Đối tượng và phương pháp nghiên cứu: tiến cứu mô tả cắt ngang. Nghiên cứu được tiến hành trên 176 bệnh nhẩn có bướu nhân tuyến giáp được chọc hút kim nhỏ dưới hướng dẫn của siêu âm tại bệnh viện đa khoa tỉnh Thái Bình. Kết quả: chẩn đoán tế bào học: bướu giáp lành tính chiếm $95,4 \%$, ung thư biểu mô tuyến giáp thể nhú chiếm $3,4 \%$, nghi ngờ là $1,2 \%$. Chẩn đoán mô bệnh học: bướu giáp keo lành chiếm tỷ lệ 70,9\%, UTBM thể nhú $19,4 \%$, u tuyến giáp thể nang 9,7\%. Giá trị chẩn đoán tế bào hoc choc dưới hướng dấn của siêu âm: đô nhay: $6 / 6=100 \%$, độ đặc hiệu: $23 / 25=92 \%$, đổ chính xác: $29 / 31=93,5 \%$, giá trị chẩn đoán $(+): 6 / 8$ $=75 \%$, giá trị chẩn đoán $(-): 23 / 23=100 \%$.

\section{SUMMARY}

\section{COMPARISON OF FINE NEEDLE ASPIRATION UNDER ULTRASOUND GUIDANCE WITH HISTOPATHOLOGICAL OF THYROID NODULES IN THAIBINH IN 2019}

Objectives: To compare the diagnosis of fine needle aspiration (FNA) under ultrasound guidance with histopathological diagnosis after surgery of thyroid nodules in Thai Binh in 2019. Objects and research methods: cross-sectional descriptive research. The study was conducted on 176 patients with thyroid neoplasm using FNA with ultrasound guidance at Thai Binh General Hospital. Results: cytological diagnosis: benign thyroid goiter accounts for $95.4 \%$, papillary thyroid carcinoma accounts for $3.4 \%$, and suspected to be $1.2 \%$. Diagnosis of histopathology: $70.9 \%$ goiter, $19.4 \%$ papillary carcinoma, $9.7 \%$ follicular thyroid tumor. Compared with histopathology, clinical examination and FNA under ultrasound guidance is method with a sensitivity of $100 \%$, specificity of $92 \%$, accuracy of $93.5 \%$, positive predictive value of $75.0 \%$, negative predictive value of $100 \%$.

\section{I. ĐẶT VẤN ĐỀ}

Bướu nhân tuyến giáp là một bệnh lý tương đối phổ biến, chiếm khoảng 4-7\% dân số, trong đó đa số là lành tính, chỉ có khoảng 4 - 5\% là ác

\footnotetext{
${ }^{1}$ Trường Đại hoc Y Dược Thái Bình

Chịu trách nhiệm chính: Trần Mạnh Hà

Email: manhha.tbump@gmail.com

Ngày nhận bài: 18.8.2021

Ngày phản biên khoa hoc: 15.10.2021

Ngày duyệt bài: 21.10.2021
}

\section{Trần Mạnh Hà ${ }^{1}$, Nguyễn Thị Thanh Hà ${ }^{1}$}

tính. Bệnh thường gặp ở nữ giới với tỉ lệ nữ/nam là 5/1, hay gặp nhất ở độ tuổi 30 - 59 tuổi [1]. Trong hâu hết các trường hợp, bệnh phát triển âm thâm, không có biểu hiện lầm sàng nên thường được phát hiện muộn. Các triệu chứng chỉ biểu hiện khi u to chèn ép các cơ quan lân cận hoặc di căn hạch cổ trong bướu ác tính. Hiện nay có rất nhiều loại xét nghiệm được sử dụng trong chẩn đoán bướu nhân tuyến giáp như siêu âm, chọc hút kim nhỏ, xạ hình tuyến giáp, chụp cắt lớp vi tính, sinh thiết tức thì.... Trong đó, siêu âm và chọc hút kim nhỏ được coi là những phương tiện chẩn đoán rất hiệu quả giúp phát hiện sớm và tìm hiểu bản chất của bướu nhân. Tuy nhiên, cả siêu âm và chọc hút kim nhỏ vẫn còn hạn chế trong đánh giá bản chất của tổn thương tuyến giáp nếu sử dụng riêng rẽ. Tại Thái Bình chưa có đề tài nghiên cứu về chọc hút kim nhỏ dưới hướng dẫn siêu âm trong chẩn đoán bản chất bướu nhân tuyến giáp. Vì vậy, chúng tôi tiến hành đề tài này với mục tiêu: Đối chiếu kết quả chẩn đoán tế bào học dưới hướng dẫn của siêu âm với chẩn đoán mô bệnh học sau phẫu thuật.

\section{II. ĐỐI TƯỢNG VÀ PHƯƠNG PHÁP NGHIÊN CỨU}

1. Đối tượng nghiên cứu. Nghiên cứu gồm 176 bệnh nhấn có bướu nhân tuyến giáp được khám và điêu trị tại các khoa Nội tiết, khoa Ung bướu bệnh viện đa khoa tỉnh Thái Bình trong khoảng thời gian từ tháng 1/2019 - 6/2019.

\section{Phương pháp nghiên cứu}

2.1. Thiết kế nghiên cứu. Nghiên cứu được tiến hành theo phương pháp tiến cứu mô tả cắt ngang.

2.2. Cõ̃ mấu và chọn mẫu. Chúng tôi chọn mẫu thuận tiện, lấy tất cả bệnh nhân có đủ tiểu chuẩn để đưa vào nghiên cứu. Số bệnh nhân trong nghiên cứu là 176.

\subsection{Các bước tiến hành nghiên cứu}

2.3.1. Thu thập thông tin

- Thu thập các thông tin chung: tuổi, giới...

- Kết quả tế bào học chọc hút kim nhỏ dưới hướng dẫn của siêu âm

- Đặc điểm mô bệnh học sau phẫu thuật: typ mô bệnh học, tình trạng hạch vùng (nếu có)...

2.3.2. Kỹ thuật chọc hút kim nhỏ dưới hướng dẫn siêu âm

- Sát trùng vùng tuyến giáp chọc hút đã được 
xác định trên lâm sàng và trên siêu âm.

- Xác định lại vị trí u giáp trên siêu âm, đường vào $\mathrm{u}$ gần nhất và dễ nhất.

- Cố định vị trí cần chọc, tay cầm kim có gắn bơm tiêm đâm qua da vào tổn thương và theo dõi đường đi của kim chọc trên màn hình siêu âm.

- Hút dưới áp lực âm để dịch chọc vào trong lòng kim. Cố định mũi kim trong khi hút để tránh chảy máu và làm đau bệnh nhân.

- Có thể xoay mũi kim theo nhiều hướng hoặc chọc hút nhiều vị trí trên tổn thương để lây đủ bệnh phẩm (nếu tổn thương $>1,5 \mathrm{~cm}$ ).

- Rút nhanh kim qua da (trước khi rút mũi kim cần giải phóng áp lực âm).

- Sát trùng lại vị trí đã̉ chọc, băng ép (nếu cần).

2.3.3. Kỹ thuật làm tiêu bản tế bào học và mô bệnh học thường quy

*Kỹ thuật làm tiêu bản tế bào học

- Tháo kim ra khỏi bơm tiêm.

- Kéo xilanh xuống để lấy không khí vào bơm tiêm.

- Lắp kim vào bơm tiêm.

- Nhanh chóng phụt dịch chọc ra lam kính đã ghi sẵn mã số bệnh nhân.

- Dàn đều bềnh phẩm.

- Để khô và cố định tiêu bản bằng cồn - ete tỷ lệ $1: 1$.

- Nhuộm Hematoxylin - Eosin hoặc Giem sa.

- Nhận định tổn thương trên kính hiển vi quang học. Phân loại tổn thương tế bào học theo Bethesda.

*Kỹ thuật làm tiêu bản mô bệnh học

- Tất cả các bệnh phẩm được cố định bằng dung dịch Formol 10\% trong 12 giờ.

- Chuyển bệnh phẩm theo chu trình kỹ thuật thường quy qua các chặng hóa chất cồn - toluen - paraffin.

- Đúc nến.

- Cắt mảnh hàng loạt trên máy Microtom với độ dày $3 \mu \mathrm{m}$.

- Nhuộm tiêu bản bằng phương pháp Hematoxylin - Eosin thường quy.

- Đọc tiêu bản: các tiêu bản được phân tích dưới kính hiển vi quang học với độ phóng đại 50 , 100, 400 lần. Xác định tổn thương và phân loại mô bệnh học theo WHO. Các tiêu bản cắt nhuộm xấu hoặc mờ nhạt được cắt nhuộm và đánh giá lại.

2.4. Các chỉ số, biến số nghiên cứu và tiêu chuẩn đánh giá

- Các chỉ số chung: tuổi, giới...

- Đặc điểm tế bào học: đọc và phân loại tổn thương theo Bethesda

- Đặc điểm mô bệnh học sau phẫu thuật (typ mô bệnh học, tình trạng hạch vùng...). Đọc và phân loại tổn thương theo WHO.
- Tính giá trị của chẩn đoán tế bào học chọc hút kim nhỏ với các chỉ số: độ nhạy, độ đặc hiệu, giá trị chẩn đoán dương tính, giá trị chẩn đoán âm tính theo công thức sau:

\begin{tabular}{|c|c|c|c|}
\hline \multirow{2}{*}{$\begin{array}{l}\text { Chấn } \\
\text { đoán tế } \\
\text { bào học }\end{array}$} & \multicolumn{2}{|c|}{ Chấn đoán mô bệnh học } & \multirow[b]{2}{*}{ Tổng } \\
\hline & Ung thư & $\begin{array}{c}\text { Không ung } \\
\text { thư }\end{array}$ & \\
\hline Ung thư & $\begin{array}{c}\text { A (Dương tính } \\
\text { thật) }\end{array}$ & $\begin{array}{l}\text { B (Dương } \\
\text { tính giả) }\end{array}$ & $a+b$ \\
\hline $\begin{array}{l}\text { Không } \\
\text { ung thư }\end{array}$ & C (Âm tính giả) & $\begin{array}{c}\text { D (Âm tính } \\
\text { thật) }\end{array}$ & $c+d$ \\
\hline Tống & $a+c$ & $b+d$ & $a+b+c+c$ \\
\hline
\end{tabular}

- Độ nhạy (Se-Sensitivity): $S e=\frac{a}{a+c}$

Độ nhạy cho thấy khả năng phát hiện đúng những người bị bệnh.

- Độ đặc hiệu (Sp-Specificity): $S p=\frac{d}{b+d}$

- Độ chính xác: Được tính bằng chỉ số giữa âm tính thật và dương tính thật trên tổng số.

- Giá trị chẩn đoán dương tính (PPV - Positive predictive value) là tỉ số dương tính thật trên dương tính thật và dương tính giả. $P P V=\frac{a}{a+b}$

- Giá trị chẩn đoán âm tính (NPV - Negative predictive value) là tỉ số giữa âm tính thật trên âm tính thật và âm tính giả. $N P V=\frac{d}{c+d}$

2.5. Xử lý số liệu. Tất cả các bệnh nhân nghiên cứu được thu thập số liệu theo một mẫu nghiên cứu thổng nhất đã được lập. Các số liệu được xử lý bằng phần mềm thống kê SPSS 22.0.

\section{KẾT QUẢ NGHIÊN CỨU}

Biểu đồ 3.1. Phân bố bệnh nhân theo tuổi

$\square<30 \square 30-39 \square 40-49 \square 50-59 \square \geq 60$

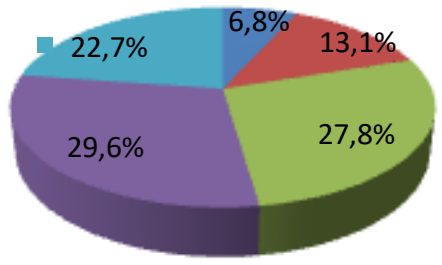

Nhận xét: nhóm tuổi có tỷ lệ mắc bệnh cao nhất là $50-59(29,6 \%)$, sau đó là nhóm tuổi 40 - $49(27,8 \%)$, nhóm tuổi < 30 chiếm tỷ lệ thấp nhất. Bệnh nhân nhỏ nhất là 12 tuổi, lớn nhất là 84 tuổi, độ tuổi trung bình là $50,07 \pm 12,47$.

\section{Bảng 3.1. Phân bố bênh nhân theo giới}

Giới tính

Nam
Số BN

19

Tỷ lệ \% 


\begin{tabular}{|c|c|c|}
\hline Nữ & 157 & 89,2 \\
\hline Tống số & $\mathbf{1 7 6}$ & $\mathbf{1 0 0 , 0}$ \\
\hline
\end{tabular}

Nhận xét: bệnh nhân nữ chiếm đa số $(89,2 \%)$, bệnh nhân nam chiếm tỷ lệ thấp $(10,8 \%)$, tỷ lệ nữ/nam = 8,3/1.

Bảng 3.2. Kết quả chẩn đoán tế bào học

\begin{tabular}{|c|c|c|c|}
\hline \multicolumn{2}{|c|}{ Chấn đoán tế bào học } & Số BN & Tỷ lệ \% \\
\hline \multirow{2}{*}{ Lành tính } & Bướu giáp keo & 148 & 84,0 \\
\hline & U tuyến nang & 20 & 11,4 \\
\hline \multirow[b]{2}{*}{ Nghi ngờ } & \multirow{2}{*}{$\begin{array}{c}\text { Quá sản tế bào } \\
\text { Tế bào không điển } \\
\text { hình }\end{array}$} & 1 & 0,6 \\
\hline & & 1 & 0,6 \\
\hline Ac tính & UTBM nhú & 6 & 3,4 \\
\hline & Tổng số & 176 & 100,0 \\
\hline
\end{tabular}

Nhân xét: kết quả chẩn đoán tế bào học cho thấy đa số các u tuyến giáp là lành tính $(95,4 \%)$, có $3,4 \%$ các trường hợp được chẩn đoán là ung thư biểu mô tuyến giáp thể nhú, còn lại là nghi ngờ (1,2\%).

Bảng 3.3. Kêt quả chẩn đoán mô bệnh học sau phẫu thuật \begin{tabular}{|l|l|l|}
\hline Chấn đoán mô bệnh học & Số BN & Tỷ lệ \% \\
\hline
\end{tabular}

\begin{tabular}{|c|c|c|c|c|}
\hline \multicolumn{2}{|c|}{ Không } & 145 & \multicolumn{2}{|c|}{82,4} \\
\hline \multirow{3}{*}{ Có } & U tuyến nang lành tính & 3 & 9,7 & 1,7 \\
\cline { 2 - 5 } & $\begin{array}{c}\text { Bướu giáp keo lành } \\
\text { tính }\end{array}$ & 22 & 70,9 & 12,5 \\
\cline { 2 - 5 } & UTBM thế nhú & 6 & 19,4 & 3,4 \\
\hline \multicolumn{2}{|c|}{} & Tống số & $\mathbf{1 7 6}$ & $\mathbf{1 0 0 , 0}$ \\
\hline
\end{tabular}

Nhận xét: trong số các bệnh nhân nghiên cứu chỉ có $31 / 176$ bênh nhân (17,6\%) được tiến hành phẫu thuật cắt bỏ khối u tuyến giáp và làm xét nghiệm mồ bệnh học, trong đó UTBM thể nhú chiếm tỷ lệ $3,4 \%$, u giáp keo lành tính chiếm $12,5 \%$, u tuyến nang ít gặp nhất $(1,7 \%)$.

Bảng 3.4. Đối chiếu chẩn đoán tế bào học với chẩn đoán mô bệnh học sau phẫu thuật

\begin{tabular}{|c|c|c|c|}
\hline Mố bệnh học & $\begin{array}{c}\text { Ác } \\
\text { tính }\end{array}$ & $\begin{array}{c}\text { Lành } \\
\text { tính }\end{array}$ & $\begin{array}{c}\text { Tổng } \\
\text { số }\end{array}$ \\
\hline Tè bào học & 6 & 0 & $\mathbf{6}$ \\
\hline Ac tính & 0 & 2 & $\mathbf{2}$ \\
\hline Nghi ngờ & 0 & 23 & $\mathbf{2 3}$ \\
\hline Lành tính & $\mathbf{6}$ & $\mathbf{2 5}$ & $\mathbf{3 1}$ \\
\hline Tổng số & $\mathbf{6}$ &
\end{tabular}

$\left.{ }^{*}\right)$ : các trường hợp tế bào ác tính và nghi ngờ được coi là dương tính.

Nhận xét: có 23 trường hợp đều chẩn đoán lành tính, 6 trường hợp đều chẩn đoán ác tính trên cả tế bào học và mô bệnh học, 2 trường hợp tế bào học nghi ngờ nhưng trên mô bệnh học là lành tính.

Giá trị chẩn đoán của phương pháp tế bào học chọc dưới hướng dẫn của siêu âm như sau:

- Độ nhạy: $6 / 6=100 \%$

- Độ đặc hiệu: 23/25 = 92\%
- Độ chính xác: 29/31 = 93,5\%

- Giá trị chẩn đoán dương tính: $6 / 8=75 \%$

- Giá trị chẩn đoán âm tính: $23 / 23=100 \%$

\section{BÀN LUÂ̂N}

Tuổi, giới. Biểu đồ 3.1 cho thấy, nhóm tuổi có tỷ lệ mắc bệnh cao nhất là từ 50 - 59 $(29,6 \%)$, sau đó là nhóm tuổi $40-49(27,8 \%)$, nhóm tuổi < 30 có tỷ lệ mắc bệnh thấp nhất. Bệnh nhân nhỏ nhất là 12 tuổi, lớn nhất là 84 tuổi, độ tuổi trung bình là $50,07 \pm 12,47$. Kết quả này cũng tương đương với nghiên cứu của Chu Thị Giang là $51,5 \pm 13,1$ [2]. Nhiều nghiên cứu trước đây cũng cho rằng tỷ lệ mắc bướu nhân tuyến giáp tăng dần theo tuổi, ở độ tuổi > 80 thì $90 \%$ là có bướu nhân. Trẻ em và thanh thiếu niên hầu như không có bướu giáp nhân, nếu xuất hiện bướu giáp nhân ở lứa tuổi này thì cần loại trừ ung thư tuyến giáp.

Nghiên cứu về giới trong bảng 3.1 cho thấy đa số bệnh nhân là nữ giới $(89,2 \%)$, nam giới chiếm tỷ lệ rất thấp, tỷ lệ nữ/nam $=8,3 / 1$. Theo Trần Mạnh Hà [3] tỷ lệ mắc bệnh tuyến giáp nữ/nam xấp xỉ 4/1, theo Chu Thị Giang [2] tỷ lệ mắc bướu nhân nữ/nam $=12 / 1$. Tuy kết quả của các tác giả có sự khác nhau nhưng đều thống nhất các bệnh lý tuyến giáp nói chung, bướu giáp nhân nói riêng đều thường gặp ở nữ giới. Có nhiều nguyên nhân dẫn tới bướu cổ như: di truyền, thiếu I - ốt, môi trường ô nhiễm, phơi nhiễm phóng xạ... nhưng đều dẫn đến tình trạng chung là sự rối loạn hệ thống miễn dịch của cơ thể, gây ảnh hưởng tới hoạt động tuyến giáp. Chính sự khác biệt trong cấu tạo cơ thể về mặt giải phấu cũng như các nhiệm vụ sinh lý của nữ giới so với nam giới là nguyên nhân chủ yếu khiến tỷ lệ mắc bệnh tuyến giáp ở nữ giới cao hơn. Ngoài ra, cơ thể phụ nữ vốn dĩ còn có yếu tố nguy cơ với việc sử dụng các loại hormone ngoại sinh từ bên ngoài như việc sử dụng thuốc tránh thai, liêu pháp hormone thay thế hay tâm lý bất an, thường xuyên căng thẳng, mất ngủ, lo âu trong cuộc sống... Những thay đổi này đều có tác động ít nhiều tới hormone tuyến giáp, tích tụ lâu dần trước khi biểu hiện ra bênh.

Đặc điểm tế bào học. Bảng 3.2 về kết quả chẩn đoán tế bào học cho thấy đa số các bướu nhân là lành tính $(95,4 \%)$, nghi ngờ $(1,2 \%)$, ung thư biểu mô tuyến giáp thể nhú $3,4 \%$. Kết quả của chúng tôi cũng phù hợp với các nghiên cứu trước đây. Theo Chu Thị Giang [2] kết quả chọc hút kim nhỏ dưới hướng dẫn của siêu âm như sau: tỷ lệ ác tính là 5,5\%, nghi ngờ ác tính là $3,4 \%$, lành tính là $91,1 \%$. Nghiên cứu của 
Nguyễn Thị Hoa Hồng [4] cho kết quả $60 \%$ lành tính, chỉ có $5,5 \%$ ác tính.

Hình ảnh tế bào học trên phiến đồ trong một số bệnh lý tuyến giáp:

- Bướu giáp keo:

+ Chất keo đồng nhất, có thể thấy tinh thể hình que, hình thoi.

+ Biểu mô tuyến nghèo nàn, thưa thớt, nhân nhỏ, đồng dạng.

- Ung thư biểu mô thể nhú: hầu hết trên phiến đồ chọc hút kim nhỏ của UTBM tuyến giáp chúng tôi thường gặp các hình thái tổn thương sau:

+ Tăng sinh tế bào rõ rệt: mật độ tế bào dày đặc trên mỗi phiến đồ. Thường nhiều hơn trong các u lành, bướu giáp đơn thuân, kể cả typ quá sản biểu mô.

+ Tế bào u thể hiện tính chất bất thường, đa hình ở các mức độ khác nhau: tế bào tăng kích thước, to nhỏ khổng đều, nhân tăng sắc, chất nhiễm sắc thô, vón cục. Đôi khi có nhiều hạt nhân to, nổi rõ, một số có nhân chia điển hình hoặc không điển hình.

+ Phiến đồ thường ít hoăc không có chất keo

+ Tổn thương kèm theo: xen kẽ tế bào ung thư còn thấy hồng cầu ít nhiều thoái hóa, tế bào lympho, bach cầu đa nhân trung tính.

Chẩn đơán mô bệnh học sau phẫu thuật

Bảng 3.3 nghiên cứu kết quả chẩn đoán mô bệnh học trong cho thây: trong số các bệnh nhân nghiên cứu chỉ có $31 / 176$ bệnh nhân $(17,6 \%)$ được tiến hành phẫu thuật cắt bỏ nhân $\mathrm{u}$, trong đó bướu giáp keo lành chiếm tỷ lệ cao nhất $(70,9 \%)$, UTBM thể nhú $(19,4 \%)$, u tuyến nang $(9,7 \%)$. Kết quả của chúng tôi tương đương của Chu Thị Giang [2] (tỷ lệ ác tính trên mô bệnh học của bướu nhân tuyến giáp là $24,7 \%$ trong đó $100 \%$ các trường hợp là ung thư biểu mô thể nhú, tỷ lệ lành tính là $75,3 \%)$, cao hơn kết quả của Trần Văn Tuấn [5] (tỷ lệ ác tính là $14,9 \%$, lành tính là $85,1 \%$ ). Điêu này có thể là trong nhóm nghiên cứu bênh nhân được phẫu thuật không mang tính ngẫu nhiên mà có tính định hướng như nghi ngờ ác tính hoặc ác tính... do vậy làm tỷ lệ dương tính của chúng tôi cao hơn.

Đối chiếu chẩn đoán tế bào học với chẩn đoán mô bệnh học sau phẫu thuật trong bảng 3.4 cho thấy: có 23 trường hợp đều chẩn đoán lành tính, 6 trường hợp đều chẩn đoán ác tính trên cả tế bào học và mô bệnh học, 2 trường hợp tế bào học nghi ngờ nhưng trên mô bệnh học là lành tính. Nếu các trường hợp tế bào ác tính và nghi ngờ được coi là dương tính thì giá trị chẩn đoán tế bào học chọc dưới hướng dẫn của siêu âm như sau:
- Độ nhạy: 6/6 = 100\%

- Đồ đăc hiệu: $23 / 25=92 \%$

- Đồ chính xác: $29 / 31=93,5 \%$

- Giá trị chẩn đoán dương tính: $6 / 8=75 \%$

- Giá trị chẩn đoán âm tính: $23 / 23=100 \%$

Kết quả của chúng tôi cũng tương đương với các nghiên cứu khác. So sánh giá trị của phương pháp chọc hút kim nhỏ tuyến giáp dưới hướng dẫn của siêu âm với kết quả của một số tác giả:

\begin{tabular}{|c|c|c|c|c|}
\hline STT & Tác giả & $\begin{array}{c}\text { Độa } \\
\text { nhậy }\end{array}$ & $\begin{array}{c}\text { Độ đặc } \\
\text { hiệu }\end{array}$ & $\begin{array}{c}\text { Độ chính } \\
\text { xác }\end{array}$ \\
\hline 1 & Trần Văn Tuấn & $83,3 \%$ & $93,5 \%$ & $79,0 \%$ \\
\hline 2 & Chu Thị Giang & $89,5 \%$ & $74,1 \%$ & $77,9 \%$ \\
\hline 3 & Pinchot SN [6] & $67,4 \%$ & $93,2 \%$ & $88,5 \%$ \\
\hline
\end{tabular}

Chọc hút kim nhỏ từ lâu đã được coi là phương pháp quan trọng nhất để sàng lọc ung thư tuyến giáp vì đây là thủ thuật đơn giản, dể thực hiện, ít tốn kém, cho kết quả nhanh với độ chính xác lên tới $95 \%$ nếu bác sỹ có kinh nghiệm. Xét nghiệm tế bào học có thể giúp bênh nhân tránh được những cuộc phẫu thuật khổng cần thiết cũng như phát hiện sớm và chính xác những trường hợp ung thư. Theo các nghiên cứu, kỹ thuâtt này có tỷ lê âm tính giả là 1 $11 \%$, tỷ lệ dương tính giả là $1-8 \%$, độ nhạy là $68-98 \%$ và độ đặc hiệu là $72-100 \%$. Siêu âm đóng vai trò quan trọng trong chẩn đoán bệnh lý bướu nhân tuyến giáp. Trên lâm sàng, viẹc phát hiện các nhân giáp có kích thước $<1 \mathrm{~cm}$ là rất khó khăn. Nếu áp dụng siêu âm vào trong chẩn đoán thì tỷ lệ phát hiện bướu nhân tuyến giáp tăng lên khoảng 10 lần so với khám lâm sàng. Siêu âm với đầu dò tần số cao, độ phân giải cao sẽ giúp khảo sát cấu trúc tuyến giáp một cách chính xác. Do vậy, nhiều tác giả như Lể Hồng Cúc, Douglas đã đề xuất nên sử dụng siêu âm như một phương tiện sàng lọc bướu nhân tuyến giáp. Nhiêu tác giả nhận định rằng kết hợp siêu âm và chọc hút kim nhỏ là phương tiện tốt nhất để chẩn đoán sớm ung thư tuyến giáp, nhất là những nhân giáp < $1 \mathrm{~cm}$, khó sờ nắn được hay cả với những nhân giáp có kích thước $>1 \mathrm{~cm}$ mà trên siêu âm có hình ảnh nghi ngờ ác tính thì cần chọc hút kim nhỏ dưới hướng dẫn của siêu âm. Với các nhân giáp đơn độc, siêu âm sẽ giúp xác định đúng vị trí cần chọc nhất là với những nhân có cấu trúc hỗn hợp âm [7], [8]. Với tuyến giáp đa nhân, siêu âm giúp chọn lọc nhân cần chọc hút dựa trên các đặc điểm siêu âm nghi ngờ. Sự phối hợp giữa siêu âm và chọc hút kim nhỏ sẽ phát huy được những ưu điểm của mỗi phương pháp, làm giảm tỷ lệ mẫu không đủ tiêu chuẩn trong khi giữ nguyên hoặc tăng độ nhạy và độ đặc hiệu, giảm tỷ lệ âm tính giả do chọc kim sai 
vị trí. Ngày nay, chọc hút kim nhỏ dưới hướng dẫn của siêu âm đã được thực hiện phổ biến ở nhiều nước trên thế giới và được xem là một phương pháp tốt nhất để đánh giá bản chất của nhân giáp. Tuy nhiên, độ chính xác của phương pháp còn phụ thuộc rất nhiều kỹ thuật thực hiện, kinh nghiệm đọc tế bào...

Trong nghiển cứu này, khi thực hiện kỹ thuật chúng tôi không gặp bất cứ trường hợp nào xảy ra tai biến và biến chứng trong và sau khi chọc. Vì vậy có thể kết luận phương pháp tế bào học chọc hút kim nhỏ dưới hướng dần của siêu âm là kỹ thuật an toàn, tỷ lệ chọc trúng tổn thương cao, nhất là với các bướu nhân nhỏ $<1 \mathrm{~cm}$, nằm sâu không sờ thấy được trên lâm sàng, có thể triển khai rộng rãi ở nhiều cơ sở y tế.

\section{KẾT LUẬN}

- Nhóm tuổi có tỷ lệ mắc bệnh cao nhất là 50

- 59 (29,6\%), nhóm tuổi < 30 chiếm tỷ lệ thấp.

- Bệnh nhân nữ chiếm đa số $(89,2 \%)$, tỷ lệ nũ̃/nam $=8,3 / 1$.

- Kết quả chẩn đoán tế bào học: bướu nhân lành tính $(95,4 \%)$, ung thư biểu mô tuyến giáp thể nhú $3,4 \%$, nghi ngờ $(1,2 \%)$.

- Kết quả chẩn đoán mô bệnh học: bướu giáp keo lành chiếm tỷ lệ $70,9 \%$, UTBM thể nhú $19,4 \%$, u tuyến nang $9,7 \%$.

- Giá trị chẩn đoán tế bào học chọc dưới hướng dẫn của siêu âm:

Độ nhạy: $6 / 6=100 \%$

Độ đặc hiệu: $23 / 25=92 \%$

Độ chính xác: $29 / 31=93,5 \%$
Giá trị chẩn đoán dương tính: $6 / 8=75 \%$

Giá trị chẩn đoán âm tính: $23 / 23=100 \%$

TÀl LIỆU THAM KHẢO

1. Nguyễn Khoa Diệu Vân (2013), "Nội tiết học trong thực hành lâm sàng", NXB Y hoc, trang 110118.

2. Chu Thị Giang (2018), Nghiên cứu đặc điểm lâm sàng, cận lâm sàng và kết quả chọc hút bướu nhân tuyến giáp tại Bệnh viện đa khoa tỉnh Ninh Bình, Luận văn tốt nghiệp bác sỹ chuyên khoa II, Đai học Y Dược Thái Bình.

3. Trẫn Mạnh ìa (2013), " Nhận xét kết quả giải phẫu bệnh và hình ảnh siêu âm trong chẩn đoán bệnh lý tuyến giáp tại bệnh viện đa khoa tỉnh Thái Bình", Y học thực hành sô 887+888, 46-49.

4. Nguyễn Thị Hoa Hông (2012), Nghiên cứu đặc điểm lâm sàng, siêu âm, choc tế bào kim nhỏ và sinh thiết tức thì trong chẩn đoán bướu nhân tuyến giáp, Luận văn tốt nghiệp bác sỹ nội trú, Đại học Y Hà Nội.

5. Trû̀n Văn Tuấn, Nguyễn Đình Tùng (2010), "Khảo sát hình ảnh siêu âm và chọc hút tế bào kim nhỏ dưới hướng dẫn siêu âm các khối bất thường tuyến giáp tai Bệnh viện trung ương Huế", Tạp chí Y Học TP. Hồ Chí Minh * Tập 14 * Phụ bản của Số $4 * 2010$.

6. Pinchot SN, Al-Wagih H, Schaefer S (2009), "Accuracy of fine-needle aspiration biopsy for predicting neoplasm or carcinoma in thyroid nodule", Arch Surg, 144:649-655.

7. Lê Hồng Cúc (2002), "Phát hiện sớm ung thư tuyến giạp bằng siêu âm kết hợp với chọc hút tế bào bằng kim nhỏ", Kỷ yếu toàn văn hội nghị chẩn đoán hình ảnh và y học hạt nhân thành phố Hồ Chí Minh mở rộng. Tháng 3 - 2002.

8. Douglas S (2002). Non - palpable Thyroid Nodules - Managing an Epidemic, The Journal of Clinical Endocrinology Metabolisme, 87(5), 1983 - 1990

\title{
KẾT QUẢ NộI SOI KHỚP GỐI CỐ ĐINHH BONG ĐIỂM BÁM DÂY CHẰNG CHÉO TRƯớC
}

\author{
Nguyễn Ngọc Sinh ${ }^{1}$, Nguyễn Vũ Hoàng ${ }^{1}$, \\ Hoàng Văn Dung' ${ }^{2}$ Vũ Mạnh Cường ${ }^{2}$, Nguyễn Thế $\mathrm{Anh}^{2}$
}

\section{TÓM TẮT}

Đă̆t vấn đề: Bong điểm bám chày dây chằng chéo trước (DCCT) được phân loại theo Meyer và McKeever là một chấn thương bong nhiều mảnh di lệch nơi bám chày của DCCT khớp gối. Có nhiều cách điêu trị qua mổ mở hoặc nội soi như: bằng vít, đinh, chỉ thép hoặc

\footnotetext{
${ }^{1}$ Trường Đại học Y dược Thái Nguyên ²Bênh viện TW thái nguyên

Chịu trách nhiệm chính: Nguyễn Ngọc Sinh

Email: nguyenngocsinh0205@gmail.com

Ngày nhận bài: 20.8.2021

Ngày phản biện khoa học: 18.10.2021

Ngày duyệt bài: 18.10.2021
}

khâu cố định. Khâu néo ép cố định dưới nội soi là kỹ thuật tiến bộ mới ít xâm nhập vẫn còn nhiều thách thức trong nghiên cứu của các phẫu thuật viên hiện nay. Mục tiều nghiên cứu: Đánh giá kết quả phục hồi về lẩm sàng và $X$ quang sau khâu qua nội soi điểu trị bong nơi bám chày DCCT bằng chỉ siêu bền. Đối tượng và Phương pháp nghiên cứu: Từ ngày 01 tháng 01 năm 2015 đến ngày 30 tháng 06 năm 2021, có 33 trường hợp bong nơi bám chày DCCT được điêu trị bằng kỹ thuật khâu dưới nội soi với chỉ siểu bền. Phương pháp nghiên cứu là nghiên cứu mô tả. Đánh giá kết quả dựa vào: đánh giá tầm vận động khớp, dấu Lachmann và điểm số Lysholm, Noyes, kết quả Xquang sau mổ. Kết quả: 33 bệnh nhân tuổi TB 30, được theo dõi trung bình 14 tháng. Điểm số trung 